\title{
Everyday life and water tourism mobilities: Mundane aspects of canal travel
}

Maarja Kaaristo (the corresponding author)

School of Tourism, Events and Hospitality Management, Manchester Metropolitan

University, Righton Building, Cavendish Street, Manchester, M15 6BG, United Kingdom.

M.Kaaristo@mmu.ac.uk

Steven Rhoden

School of Tourism, Events and Hospitality Management, Manchester Metropolitan

University, Righton Building, Cavendish Street, Manchester, M15 6BG, United Kingdom.

S.Rhoden@mmu.ac.uk

Biographical notes

Maarja Kaaristo is PhD Researcher and Associate Lecturer at School of Tourism, Events and Hospitality Management, Manchester Metropolitan University. Her main research interests include mobilities, materialites and sensory experiences in tourism. She has a MA in ethnology from University of Tartu, Estonia.

Steven Rhoden is Principal Lecturer for Tourism and For Research \& Business Engagement at School of Tourism, Events and Hospitality Management, Manchester Metropolitan University. His primary research focus is the transport experiences of tourists/leisure passengers. He has a PhD in tourism management from Manchester Metropolitan University, UK. 


\begin{abstract}
Tourism is frequently construed as unusual and extraordinary in contrast to the routines and predictability of work and home life. However, the tourism spaces are co-created through practices that are simultaneously mundane and unusual. Yet everyday touristic practices are seldom researched, especially regarding water tourism. The mundane strategies of creating the boatspace form an important part of the tourist experience of everyday life on canals of England. Movements of bodies in the space, gastronomic experiences, and hygiene practices studied here via ethnographic fieldwork (participant observation and semi-structured interviews with leisure boaters) become defining characteristics of the leisure boaters' everyday. We show that spatial practices, temporal structures and search for ontological security are essential elements of domesticating and co-creating the emergent boatspace, where physical and social space are negotiated between various actors.
\end{abstract}

Keywords: mundane; tourism mobilities; everyday life; boating; canals; narrowboat; food; hygiene; ethnography.

\title{
Introduction
}

The phenomenon of tourism is often conceived as something unusual and extraordinary; a contrast to the routines and predictability of work and home life. The tourist experience can magnify everyday life and has transformative power in the life of the individual and society (Ryan, 2010; Uriely, 2005). However, leisure time consists of more than meaningful moments and amplified emotions: in practice, non-reflexive, mundane activities and experiences intertwine with unusual ones and create a complex tourist experience (Edensor, 2007; Larsen, 2008; Löfgren, 2008). This apparent contradiction positions the phenomenon of tourism somewhere in the middle of a conceptual axis of everyday and peak experience (Maslow, 1962); in an area where the ideas and practices of the ordinary and the extraordinary blur.

The aim of this article is to identify the tourists' everyday life practices performed on the narrowboats on the canals of England. We respond to Edensor's (2006, p. 31) call that "“everyday life" should be central to future tourism research because it focuses upon the under-acknowledged routines, ordinary objects and familial interactions of tourist practice, as well as quotidian forms of excitement, creativity and small-scale, disruptive "tactics". Accordingly, with specific reference to canal holidays, we will examine the everyday 
activities that are usually thought of as unimportant and insignificant yet still comprise an important part of the actual tourist experience. Quan and Wang (2004) divide between the general social sciences approach that has focused on the attraction centred 'peak experience' and the marketing/management approach that studies the 'consumer experience' in tourism and, doing that, the latter also takes into account the supporting experiences from eating to sleeping to transport. However, this approach is limited with its strictly business and industry-orientated focus where the tourist is regarded as first and foremost a consumer which leaves little room for a more individual-centred and phenomenological approach. Therefore, there is a need to study everyday practices in tourism: as the tourist spends a lot of their time preoccupied with various mundane tasks, it is possible to identify these essential elements of the tourist experience.

Based on the data collected during ethnographic fieldwork (participant observation and ethnographic interviews) on holiday and leisure canal boating in the North West of England, we explore how everyday activities - moving about in the interior spaces of narrowboats, performing domestic tasks like preparing food and drink, and practising personal hygiene - are experienced. These activities are integral to tourists' journeying practices and thus become important strategies of negotiating the space for the holiday boaters. Everyday activities are an integral and substantial, yet very under-researched, part of the tourist experience. Therefore this paper sets out to study 'what happens in all the inbetweens of tourist life that too often are described as a pilgrimage where tourists move from one satisfying event to another, from sight to sight' (Löfgren, 2008, p. 87). This paper contributes to tourism studies by exploring the interface between mobilities paradigm and the mundane tourist activities by demonstrating that the everyday mobilities are crucial part of how tourist experiences and spaces are reconstituted. We will further illuminate an underrepresented mode of mobility, recreational canal boating, arguing for the study of habitual and ordinary in the tourist experience as a strategy of making the leisure space.

\section{Tourism and everyday: extraordinary and ordinary}

There is a traditional tendency in tourism research to view tourism as something existing outside everyday life, notably in dominant studies on the tourist experiences and in the explorations of the tourists' search for authenticity (MacCannell, 1999 [1976]; Cohen, 1979; 
Wang, 1999; Cary, 2004). In these studies, tourism is conceived as 'essentially a temporary reversal of everyday activities - it is a no-work, no-care, no-thrift situation' (Cohen, 1979, p. 181). In The Tourist Gaze 3.0, Urry and Larsen (2011, p. 4) argue that

tourism is a leisure activity which presupposes its opposite, namely regulated and organised work. It is one manifestation of how work and leisure are organised as separate and regulated spheres of social practice in 'modern' societies. Indeed, acting as a tourist is one of the defining characteristics of being 'modern' and is bound up with major transformations of paid work.

Yet, if being a tourist is one of the most important properties of being 'modern', it could be argued that this very state of being is now actually rather an important element of the mundane lifeworld too. For many people in 'the West' and the affluent from 'the rest', travel for various purposes is accessible and easy. It is part of contemporary lifestyles, an 'everyday mobility' (Hall, 2008, p. 15). The boundaries between tourism and the everyday have become increasingly blurred and travel becomes one of the important ways of performing everyday life (Edensor, 2007; Larsen, 2008; Mikkelsen \& Cohen, 2015).

The fast development of information and communication technologies in the past 25 years, widely accessible (wireless) internet and easily available portable devices enable people to work, relax and socialise in various locations of people's own choice (Nansen, Arnold, Gibbs \& Davis, 2010), often simultaneously. Consequently, it is not as important where exactly does a certain tourist practice take place (and how far away from 'home'), but rather when, why and especially how since 'extraordinary' status can be attributed to various tourist trips regardless of their familiarity or unfamiliarity (Williams \& Lew, 2015). Tourism spaces are certainly localizable, but not necessarily fixities, as they can be mobile and dispersed simultaneously in many locations, times and sociabilities.

In parallel with altered conceptions of work and leisure, tourist studies have started to pay attention to the mundane and homely in the tourist experience. Edensor (2001) called attention to this under-researched issue, noting that even though tourism is still very much connected to the idea of escaping from normativity, the everyday routines and practices are part of the baggage that the tourists take with them when they travel. Such habits and responses resonate in Larsen's (2008) project of 'de-exoticising' tourist travel. For Larsen, the idea of 'everydayness' is a useful concept when analysing the tourist experience, allowing us to see how tourist spaces are actually full of everyday practices and directing us to look 
beyond the fixed dichotomies of work and leisure, everyday and tourism, ordinary and extraordinary. Our everyday lives are made of various mundane habits, activities and routines that become non-conscious since they are ingrained in our lives via repetition. When these routines are upset, such as in the tourism setting, they can create psychological discomfort and unease (Edensor, 2010) and therefore one of the strategies for being a tourist is actually to seek out the familiar and homely in an unfamiliar space. Mikkelsen and Cohen (2015, p. 676) show in their study of domestic caravanning how 'experiences of freedom can occur in close proximity to home and through engaging in ordinary doings [---], and this mundanity can transform into perceived extraordinary experiences.' This means that tourists are constantly in the process of domesticating their spaces, creating and adjusting to new routines and habits which then become an important part of the overall experience.

As the boundaries between tourism, leisure, education, sports, hobbies, everyday life and virtual travel are disappearing, many researchers have moved away from both industryorientated definitions based on overnight stays as well as the various classifications of different types of tourists. They are rather subscribing to more flexible ideas that see tourism as one of the ways among many of being in the world (Obrador, 2003), a mode of seeing and sensing it (Franklin \& Crang, 2001). Following Gale (2008, p. 2), we will rely on the mobilities perspective because 'the turn to mobility in the social sciences calls for the decentring of tourism studies so that, rather than being preoccupied with the tourist and travels to distant lands, it recognizes the interconnected mobilities of a variety of individuals [original emphasis] ... voluntarily on the move'.

\section{Mundane mobilities and water tourism}

Mobility, generally understood to be socially produced motion (Cresswell, 2006), has become an increasingly important concept in contemporary human/cultural (critical) geography, tourism studies, social and cultural anthropology, sociology, and other disciplines. Termed as 'new mobilities paradigm' (Sheller \& Urry, 2006; Urry, 2007), this way of thinking entails both local and global movements of people, objects, ideas and information (Hannam, Sheller \& Urry, 2006). 'Mobility is practiced, it is experienced, it is embodied' (Cresswell, 2006, p. 3) and physical travel involves 'lumpy, fragile, aged, gendered, racialized bodies encountering other bodies' (Urry, 2007, p. 272). Travelling is a process of (physical) 
movement, simultaneously functional and full of meanings that includes being co-present and interacting with material objects from vehicles to guidebooks to technological applications. Accordingly, the mobilities perspective allows us to highlight the social processes that take place between individuals and groups, as well as the study of spaces where moving subjects encounter each other in their (everyday) interactions.

Mirroring the recent move to study the mundane within tourism, the past decade has seen growing interest in everyday and 'mundane mobilities' (Edensor, 2007): the customary routines, cultural conventions and normative performances of different types of mobility. This perspective suggests looking more closely to the various mobile everyday incidences and performances that are characterised by their regular and everyday occurrence, unreflexivity and habituality (Binnie, Edensor, Holloway, Millington \& Young, 2007). However, most of the literature discussing various mobilities as essentially everyday practices is still focused only on particular types and forms such as automobilities (Merriman, 2009) or commuting (Bissell, 2014). Although these treatments of movement do contrast with the earlier focus on large-scale mobilities, such as international mass tourism, the small-scale mobilities of (and also on board of) various vehicles, which constitute an important part of place-making have not received sufficient attention.

In addition, Anderson and Peters (2014) criticize human geography for being too terra-centric and neglecting waterscapes that are also vitally connected to the everyday lives of the contemporary individual. Anim-Addo, Hasty and Peters (2014, p. 337) express the same sentiment declaring that 'in the burgeoning field of mobilities studies, the seas and all that moves in, on, across and through them, have not been embraced with the same enthusiasm as mobilities ashore.' We concur, finding a relative paucity of extant research in this area. Where it exists, scholars concentrate typically on embodied experience of various types of oceanic and sea-going vessels, especially cruise ships (Klein, 2008), but also sailboats (Kleinert, 2009), cargo vessels (Sampson \& Thomas, 2003) and ferries (Vannini, 2012).

Yet, for all the calls to fill the 'watery void' (Anderson \& Peters, 2014, p. 8) in cultural and critical geography, the slowly but steadily growing literature on water mobilities concentrates on oceanic and sea mobilities, and research on inland water bodies, such as rivers, lakes and especially canals is relatively infrequent. Canals have been looked at as desirable leisure environment in urban settings (Coles, Millman \& Flannigan, 2013) that can also be digitally mediated and enhanced via engagement with mobile technologies and social 
media (Jordan, 2015) and Bowles has studied permanent canal boat dwellers ('liveaboards') perceptions of security (2014) and temporality (2016). Regarding leisure and tourism however, most treatments of either river (Prideaux and Cooper, 2009), lake (Hall and Härkönen, 2006) or canal (Fyall, Oakley \& Weiss, 2000; Monahan \& Spencer 2004; Shipley, 1999; Tang \& Jang, 2010) tourism are written from the management and marketing perspective. Studies taking a more individual-centred approach to inland waterways boating tourism are rare. Johns and Clarke (2001) identify themes of 'nature', 'adventure', 'fun', 'otherness' and 'activity' in the discourses of holiday boaters on the rivers and lakes of Norfolk Broads, UK. Fallon (2012) analyses published memoirs about boating on Britain's narrow canals in the framework of slow tourism, showing how canals provide relaxing experiences and can be seen as an antidote to the fast pace of the contemporary technologydriven world. However, there are no primary empirical studies of the individual contemporary tourist experience on canals in the UK, and thus the study of this particular water tourism mobility is overdue. Therefore, this paper is a response to Tang and Jang's (2010, p. 437) observation that '[e]ven though many canals are transformed from commercial shipping waterways to tourism destinations, little effort has been made to understand the contemporary phenomenon of canal tourism in academia.'

\section{Studying England's canals}

\section{Context}

In order to analyse the everyday strategies of holiday boaters, we concentrate on recreational canal travel in north western England, UK. There are over 2,000 miles (3,200 km) of navigable inland waterways in the UK owned and managed by different navigation authorities, the two largest being the Canal and River Trust, and the Environment Agency (Maritime and Coastguard Agency, 2014). Canals have undergone a transformation from being extremely important transport links during the industrial revolution in the $18^{\text {th }}$ and early $19^{\text {th }}$ centuries, to being left largely derelict after the introduction of the railways in the first quarter of the $19^{\text {th }}$ century. They were again used for freight traffic during World War II. In 1947 most of the canal network was nationalised and the use of canals transitioned to cruising/leisure predominantly because many of formerly derelict canals were restored (Hadfield and Biddle, 1970; Bagwell and Lyth, 2006). In the 1980s and 1990s, the number of leisure boaters on the canals increased and the use of canals and their adjacent land has since 
extended for a variety of uses, including walking, angling and cycling in rural and urban areas. In 2014, the UK's canals and rivers attracted approximately 19.5 million visitors (Canal and River Trust, 2015) although, with no precise method to capture and measure canal and river use, it is likely that this number is an underestimate. With nearly half of the 64.6 million population of the UK residing within five miles (eight kilometres) of a waterway, we maintain there is potential for increased leisure usage in future.

This paper focuses specifically on a fairly neglected topic, leisure and holiday boating on England's canals which we define as cruising from a day to several weeks on self-drive boats for recreational purposes. More specifically, we study spending holidays on narrowboats, which is a type of canal boat designed to fit the narrow canals of UK with a maximum width of $6 \mathrm{ft}$. 10 ins. $(2.08 \mathrm{~m})$ and a maximum length of $72 \mathrm{ft} .(21.95 \mathrm{~m})$ (See Figure 1). There are currently more than 32,000 licensed boats (including narrowboats, river cruisers and wide beam boats) on the canal network, including private boats used as homes (see Bowles, 2014; 2016) or second homes, boats co-owned by groups of people for holiday purposes, and hire-boats, trip-boats and restaurant-boats (Canal and River Trust, 2015).

\section{Methodology}

The methodological framework of this study is ethnographical. The fieldwork was conducted by the lead author in the North West of England in 2014-2016, on the canals in and surrounding Manchester - Rochdale Canal, Ashton Canal, Macclesfield Canal, Peak Forest Canal, Bridgewater Canal, Leeds \& Liverpool Canal and Trent and Mersey Canal (See Figure 2). It consisted of participant observation (individual boat-trips where the lead author would either hire a boat or accompany boaters on their trips) and semi-structured interviews with leisure boaters who were recruited either during the boat trips or at various waterways related events. All of the boaters who were researched were aware of the reason for the lead author's presence on their trips and in all cases, written informed consent was obtained prior to data collection. The lead author, an Estonian woman in her 30s, did not have any experience of canal boating before starting this research and, as an outsider researcher, engaged in 'active participation' (Dewalt, Dewalt \& Wayland, 1998) during the fieldwork. This meant getting to know the boaters, learning how to work the locks and steer the boat, obtaining the boaters' vocabulary and familiarizing herself with the (leisure) boating and canal enthusiasts' community in the North West England. She now inhabits 'the space between' (Dwyer \& 
Buckle, 2009) outsider and insider, having become a complete member (Adler \& Adler, 1987) of the studied group, and combining the identities of a researcher as well as a holiday boater.

Fifteen in-depth interviews were conducted with British leisure boaters. The profile of interviewees comprised different ages (from 24 to 75 years) and nine males and six females, with various boating experiences (ranging from one trip to many years of extensive boating experience) were interviewed. The interviewed boaters travelled either as couples, with family or a group of friends. Interviews addressed various themes and topics including reasons for boating, everyday life, physical experiences of boating, safety, sensory aspects of boating, tempo and rhythm. Each interview was recorded and transcribed verbatim with the interviewees' consent and all the quoted boaters have chosen to use their real names. The lead author kept a fieldwork diary recording the observations, experiences and discussions with various people encountered on and near the canals, from boaters to volunteers working to maintain the canals to passers-by, after every encounter during the fieldwork.

Both the studied group (holiday boaters) and the place (the canals) are not permanent and stable in any way, but temporary, mobile and unfixed. The field is always changing, as various groups of people move about the canals for different amounts of time. Accordingly, we have produced a mobile ethnography, 'trying to move with, and to be moved by, the fleeting, distributed, multiple, non-casual, sensory, emotional and kinaesthetic' (Büscher, Urry \& Witchger, 2011: 1) in the wider canalscape. This meant tracing the boaters both geographically (boating on various canals with different people) and temporally (talking about trips that had taken place as long ago as the 1970s). These data were analysed subsequently, and the major themes in the empirical data (embodied movements, gastronomic experiences and personal hygiene practices) as well as the meta-themes - spatial practices, temporal structures and ontological comfort strategies - emerging from the themes are reported next.

\section{The embodied movements of the tourist everyday}

When on a boat, one has to (re)adjust to the restricted space of even the longest of narrowboats, which limits movement considerably. The success of walking from one end of a boat to the other, which can seem a straightforward task, would actually depend on various 
individual properties such as height, weight or a sense of balance. For example, one of the research participants, a tall and quite large man, could not walk through the sleeping area of the boat, with bunk beds on both sides, in straight direction and always had to go sideways. Therefore, he avoided doing that whenever possible and instead tended to use the gunnel, an exterior, upper edge of the boat's hull sides. Walking the gunnel is an activity that requires a certain confidence in one's sense of balance as you move along the extremely narrow edge holding on to the grab rail, following the basic rule that either two feet and a hand or two hands and a foot have to be secure at all times. Stepping onto and off the boat (usually from the stern, i.e. the back of the boat) also needs consideration of variables such as how far away boat from the bank the boat is moored, whether you need a plank, or whether the boat is moving (when hopping back aboard after working the lock). When dis-/embarking from the bow (front), one needs climb up a step on the edge of the boat, which poses a risk of slipping in wet conditions.

In order to fit sometimes up to twelve people around the table on a boat, there is usually a system of fold-up chairs and removable table-plates in place. One of the interviewed boaters describes the experience as being 'trapped' if you happened to sit in the middle. Indeed, leaving the table for a short while means several people having to perform an exercise of standing up, letting the person pass, sitting down again, and repeating the whole procedure in reverse once the person comes back. Once seated, one would usually limit their moving about as much as possible. Bodily contact however cannot always be avoided: 'Even if, like, two small people shimmied, you would end up rubbing bums or something like that. To try to slide past each other. But it wasn't an issue really at all!' (Katie, 24). The occasional physical contact of bodies that would not be regarded appropriate, acceptable, or comfortable in different environment such as on the land becomes a new normality in the boatspace as 'spaces are - at least in part - as moving bodies do' [original italics] (McCormack, 2008, p. 1823).

Since narrowboats rarely have separate sleeping cabins due to their layout, there is very little room for privacy on-board. This makes the bathroom effectively the only place where one could actually be alone - for example when boating with a group of people, there would be nowhere else to change clothes if one wanted to do that in private. 'Being on a boat, together in close proximity, can be tough at times,' a research participant who was boating just with her partner, contemplated. Another boater described feeling uneasy when asking people sitting around the table to step aside when she needed to go out for a cigarette. This 
made her feel self-conscious, as she perceived having to ask to pass as an invasion of privacy that brought attention to her smoking while usually she would 'just sneak off and no one notices.'

The boaters have to adapt to the close physical proximities in the limited and limiting space and the resulting lack of privacy by developing a complicated choreography of bodies of various sizes, genders and ages. This is achieved by planning, making up strategies on the go and getting used to navigating in the unfamiliar space. The lead author, for example, acquired a habit of sitting down on the sleeping bunk to make room for the person passing when boating with a bigger group. Other tactics include planning ahead - looking as far ahead as possible on the boat to make sure if anyone is coming before making their way to the other end. Certain spots would also be identified, such as next to the bathroom or galley area where there would be more room so that two people could pass each other without actually having to touch. When showering, the body would have to adapt to the restricted space of the walk-in shower, and the movements of the arms would have to be limited so that the body would take as little space as possible. If the boat has a double berth, it has to be made every night as otherwise it would obstruct people from moving about during the daytime. Overall, as Richard (67) puts it: 'I think a newcomer, going into a narrowboat, compared with a broad beam boat would think, this is low, this is narrow. But you get used to it!'

These spatial practices that have been learned during the day have to be renegotiated at night when the boater would have to carry a torch in order to navigate the un-illuminated towpaths and the boat itself in sometimes complete darkness. The mobility of the boat depends on the diurnal cycle as the boaters would normally cruise during the day and start looking for a place to moor for the night as soon as the sun starts to set. Cruising in the dark is not allowed for the hired boats (and the vast majority of private ones tend to moor up in the dusk). The temporal rhythm of canal boating is determined by the slow (maximum four miles $(6.4 \mathrm{~km})$ per hour) mobility of the boat, one of the defining characteristics of a canal holiday (Fallon, 2012). The holiday boaters usually need to cover certain amounts of distance each day in order to reach the destination and/or get back on time, which then in turn has a strong effect on their 'personal time maps where the experience of time contains long, slow continuities [that can be] followed by sudden ruptures' (Bowles, 2016, p. 104).

The close physical proximity of other boaters in the limited space where movement is restricted is an important factor in regards to the altered spatial practices. This, in turn, brings 
forth the lack of privacy on the boat, which means that the boundaries of public and private dissolve, change and obtain new meanings. The narrowboat, a 'floating corridor' as some boaters call it jokingly and endearingly, thus becomes a mobile place created by the boaters via developing certain choreographies, patterns of movement and temporal schedules, constantly re-negotiated with and in regards to other boaters, non-human animals and material environment.

\section{The gastronomic experiences: food and boating}

Larsen asks tourism scholars to pay attention to the everyday practices of the holiday in order to determine 'what tourists do when vacationing' (2008, p. 31). When posed this question, Kirsten (32) replied, 'I tend to... this is going to sound terrible. I tend to make the tea. I honestly tend to make tea.' Food and drink play an important role in domesticating the tourism space of the narrowboat. Making tea, in particular, is one of the most frequent and important activities - and a device for creating sense of homeliness and belonging - on the boat. When an elderly leisure boater, John, invited the lead author onto his boat after half a day of helping him with the locks in central Manchester, he first offered her a cup, which they drank while chatting. Later, when travelling on along the canal and, since John was steering his boat, he asked her to 'make a brew' (cup of tea). Under his directions, given from the stern of the boat, the author tried to navigate the unfamiliar galley, and although she spilt some water and hastily tried to wipe it up so that no-one would notice (they did), she finally presented him and another boater helping him with the locks with a cup of tea, a bit of milk, no sugar. John took a sip and said, 'First thing that a boater needs to learn is how to make a proper tea and she's got that down pretty nicely.' As apparent from the lead author's 'rite of passage' (Gennep, 1960 [1909]) into that particular boatspace, food and drink are extremely important aspects of making the narrowboat spaces homely and familiar. Food can be 'the extension of the ontological comfort of home' (Quan and Wang, 2004, p. 301) in tourism settings and regular tea (or, to a much lesser extent, coffee) breaks serve as structuring elements of the British everyday, on the boat just as on land.

Mealtimes provide most important points of structure to canal boating through their regular (and routinized) occurrence as well as their impact on the boat's mobility. A typical day for the holiday boaters would start with putting on a kettle to make tea or coffee (just like 
at home). They would then have breakfast (cereal, porridge or toast with jam, peanut butter, syrup, honey or Marmite) and after some hours of cruising moor up for lunch, usually prepared and eaten on the boat. Depending on the number of people and the division of various tasks, the boat would usually keep moving while the lunch - sandwiches, baked potatoes, salad, full English breakfast or soup (the latter is especially common when travelling in colder weather) - is being prepared. Cooking food, making tea or coffee and doing the washing up also gives those not steering the boat something to do. As the days on the canal spent cruising can also be quite uneventful, dull or sometimes boring (especially with bad weather when taking a walk on the towpath or sitting outside in the bow or stern is not especially inviting). Due to the limited space however, there is usually room for no more than two people in the galley, and preparing the food often means performing a carefully coordinated and well-practiced series of movements.

After lunch, the boaters would usually visit some nearby attractions or museums, go shopping or for a walk, or continue cruising, before mooring up again for the dinner and night at sunset. The evening meals would again be either cooked on the boat or the boaters would visit pubs along the sides of the canals, of which there are many. The pubs are usually listed in waterways guides for boaters, such as 'Nicholson's' (e.g. Mosse, Frew \& Malcolm, 2013), where boaters can have fish and chips, pies and hamburgers with local ales, sometimes followed by a pub quiz, another element of homely and familiar in the overall experience. However, food also becomes a means to see the ordinary in a different way on the boat and preparing and consuming it can be perceived as transformative and exceptional experience:

Just moor up in the countryside, watch the moon come up, we had that one night, beautiful. And they [the friends] had taken fairy lights and we just pulled in to the canal side, we had the moon rising over the Pennines, the sun setting over the Winter Hill in the distance, the stars coming out. It's a warm night, put the fairy lights on the boat, and we had a barbecue on the canal side. (Barry, 66)

The meal that Barry describes became a peak touristic experience, where the food itself may be familiar, but is delivered and consumed in a novel manner. They also enhanced the natural environment (countryside, moon and the stars) via adding the fairy lights, which intensified the total experience further.

In addition to providing regularity and structure to the boating, food becomes a means of seeing and perceiving the ordinary in a novel way. Food is an essential part of the tourist 
everyday, and since it is consumed daily and with regularity, becomes a temporal structuring device as well as source of ontological security and comfort. Everyday cooking (as well as grocery shopping or locating the nearest pub) influences both the boat's mobility as well as the movement patterns of those on board as various spatial practices emerge. The food can also be perceived as transformative, since elements of everyday life are often magnified in tourism settings (McCabe, 2002) and preparing and consuming meals on the boat become one of the means of how the ordinary is transformed into extraordinary within the tourism spaces.

\section{Personal hygiene practices on the boat}

Toilets and bathrooms are mechanisms of translation between nature and culture and showcases for what is seen as culturally acceptable and what is not (Gramigna, 2013), as the norms for bathroom use (when, where, and how) differ both in time and space (Leone, 2012). The questions of dealing with bodily waste are possibly a site of abjection 'too "squeamish" for the focus of geographers' (Longhurst, 2000, p. 66). This is why notions, ideas and taboos connected to subjective and individual bodily experiences of bathroom use rarely get mentioned in the literature on tourism geography. A notable exception is Falconer's (2012, p. 111-121) analysis of female independent travellers who use narratives about dealing with various secretions and fluids such as vomit, urine, excretion, infection and menstrual blood for strengthening and legitimising their identities as seasoned travellers.

The toilets on the modern narrowboats differ from their counterparts on land in one main way: their contents need to be stored for a period of time on the boat for later disposal which can thus mean having to re-encounter your bodily waste. The toilets themselves usually look more or less like the customary ones with either a button for flushing or a train or plane like systems with a lever that opens and closes the valve in the toilet bowl. Some hire companies also ask the boaters not to "put anything down the toilet unless you have eaten it first' (as signs in the bathrooms sometimes read). Most of the modern boats have either the cassette (which has to be manually removed and emptied at the designated station) or the pump-out system that lasts longer (where the waste is pumped out in the station). Hire-boats tend to be equipped with the latter and the pump-out is not usually an issue for small groups of hire-boaters on shorter trips (a week or less) because it gets done by the hire company. 
Thus the holidaymakers' contact with their bodily waste is kept at a minimum and the boat's facilities could almost be perceived as ordinary as those regularly used.

Nevertheless, the topic of waste management on the boat, when confronted with it, can evoke some uneasiness and awkwardness in less experienced boaters and, accordingly, it is discussed using expressions such as 'dealing with ... the nasty bits.' Some of the older boats also have 'bucket and chuck it' type portable toilets, which one of the research participants recollected with great nostalgia, as for him this uncomfortable aspect of boating seemed to be a testament to the boater's way of living that is more 'close to nature'. On the other hand, another boater, when actually seeing the 'bucket' being carried to the designated sewage disposal station made gagging noises and demonstrated both verbally and with his body language his aversion to the sight, thus perfectly illustrating Douglas's (1966) argument that dirt is a 'matter out-of-place'.

As apparent from Falconer's (2012) account, the narratives on the bodily excretions usually deemed 'worthy' of recounting are incidents that are perceived out of ordinary and very different from the everyday bathroom practices at home. Holiday boaters, likewise, tell stories for pure amusement and 'shock value': the embarrassing incidents that concern the specificities of the boat toilets that could not happen on the land. These stories for example include full waste tanks while having guests on board while the boat is frozen in the canal and therefore cannot move to the sewage disposal point; full cassettes falling on the towpath and breaking; having to dig a hole and bury the contents of the cassette; or having to deal with the smell for long periods of time due to either misuse or breaking down of the toilet. A story was recounted to the lead author on a boat trip after dinner for many laughs (and quite obviously not for the first time) about an earlier trip on a converted traditional workboat with a simple portable toilet located in the bow of the boat. An inexperienced helmsman had crashed into a bridge causing the cover on the bow fall off, revealing another boater who had been using the toilet, knocked on the floor with his trousers down and contents of the toilet spilt all over him.

Most of the time, however, the holiday boaters deal with everyday bathroom and toilet use of the boats: negotiating the small space of the bathrooms and shower stalls where taller people can find themselves 'crouching'; the bathroom schedules in the mornings; the need to wait for the water to heat on some boats; the thin bathroom walls giving very little privacy; and, having to share one or two bathrooms between up to 12 people. These mundane activities give the boaters little room for the heroic narratives. They go about these practices, 
having to adjust to various material and social conditions, in addition to limitations that bring social and gender relations as well as different routines and habits, to the foreground. The small-scale mobilities aboard the boats are also influenced by the fact that the boat itself is moving and if there are just two people on boat (often a couple) one of them has to steer while the other uses the bathroom. This means that bodily functions can influence the mobility of the boat as well as rearrange the individual micro-mobile patterns on board as one boater in his forties explains:

We'd stop and have a break. The thing with [drinking is]... the more you take in, the obvious thing for that is - take it out. My wife does not like steering the boat so we have to wait for a long run, straight run, with no one in sight for me to disappear and go and 'spend a penny' [go to the toilet]. So you're conscious that when she keeps asking me that do you want a brew, it's like, I'd love a brew but not really because I'm going to have to go to the loo. So yes, you get used to using the toilet quickly as well...

Potable water is another organising materiality of boat's mobility: a water tank on a narrowboat (that holds 110 gallons (500 litres) on average) is a significant factor of how the boaters plan their routes. The boaters are managing a network of heterogeneous elements such as the water points (and knowledge of them obtained via physical guidebook, a canal route planner website or experience), the number of people on the boat and an estimate of how much water is used for washing and cooking. Some of this knowledge can only be obtained by the experience as the water tanks do not have gauges on them, which is why there are no means of telling exactly how much water is left in the tank and the (sometimes imagined) threat of running out of water troubles the more inexperienced boaters. Water, therefore, serves as a temporal structuring device both for the mobility of boat as well as the boaters on board.

The bathrooms are spaces where bodily boundaries are broken and then fixed again, where bodies hide and are hidden from public view and a variety of bodily fluids are managed and mediated (Longhurst, 2000). On the boat, the physicality of the human bodies is often brought to the momentary centre of attention through everyday encounters and thus serve as reminders of the normative boundaries. Various bathroom-related practices become part of the cluster of activities and processes of co-creating the boatspace where numerous bodily, social and cultural experiences and ideas come together. The boaters experience the bathrooms both as familiar and unfamiliar and they domesticate these spaces via various mundane spatialities and practices. 


\section{Conclusion: Domesticating the everyday tourist boatspace}

In this paper we analyse various mundane practices which tourists perform in order to create the everyday boatspace on the canals of North West England whilst on narrowboating holidays. By analysing the links between everyday life, water mobilities and tourist practices, we demonstrate that mundane and everyday interactions and habits are central elements of the mobile practices of holiday boaters. We show that boatspace is co-created and coproduced by various actors as a site of embodied as well as emotional intersection. The data analysis revealed three key elements of holiday boaters' everyday: embodied movements, gastronomic experiences and personal hygiene practices. From these elements, three metathemes were induced - spatial practices, temporal structuring devices and strategies for achieving ontological comfort. These meta-themes are the key elements of the process of domesticating and producing the mobile boatspace and represent the main theoretical contributions of this paper.

Performing various embodied choreographies on board of the boat become means of creating the space and using its various properties in order to make it familiar and comfortable. Limited narrowboat space is constantly renegotiated: whether eating, sleeping, using the bathroom or moving about on the boat. This also means renegotiating the relationship with your own physical body as well as its relationship with other bodies. The mundane mobility of the boat is thus co-created by simultaneous movement of the vessel and the spatial practices of the bodies on board of where interactions with various material objects, and human and non-human animals are co-performed. The holiday boaters adapt to the confined spaces in embodied ways that become a form of everyday mobility and make an important part of creating the boatspace; just as a caravan in Crouch's study, the narrowboat too 'provides a means of mobility and of temporary dwelling, convenience and romance' (2001, p. 64).

The temporal structures of boating emerge from the mobility of the boat, the diurnal cycle as well as the regular everyday activities such as preparing food and drink or following bathroom schedules. Mealtimes and tea (or coffee) breaks create a great sense of anticipation for the time to start both preparing and consuming the food and drink when boating. These breaks are a welcome change as well as extremely important structuring device for the days 
spent on the canal. The routines pertaining to bathroom use also play an important role, as they have to be negotiated between people on the boat and thus contribute to the individual and consequently the collective time maps of the boaters. Longer periods of relative continuity (cruising on a long lock-free stretch of canal) alternate with various discontinuities (stopping at the locks, for lunch, taking the water, pumping the toilet out, shopping, mooring up for the night, as well as encountering unanticipated events such as stoppages, broken locks or lack of (suitable) mooring space). The temporal scaffolding of boating is therefore determined by the 'stop-start' (Bowles, 2016) nature of boat's mobility combined with the everyday interactions, routines and schedules developed and performed on the boat.

The attempt to make the boat homely and comfortable - the search for ontological comfort - is another important aspect of domesticating the boatspace. Instead of looking for unfamiliar spaces and places, some people want to produce a familiar environment that gives them ontological security and familiarity while travelling (Mikkelsen \& Cohen, 2015). This is achieved via various practices such as filling the unfamiliar space with familiar and personal objects such as food or luggage, but also via performing different spatial everyday practices of purchasing, preparing and eating the familiar food. The safe and homely boatspace however comes into being via negotiating new and sometimes unexpected mundane elements into the equation as well: for example being forced to think about the waste and thus having to actually acknowledge the mundane in tourist experience and needing to use various coping strategies such as humour or verbal and nonverbal expressions of disgust. As such, the mundane becomes central in the tourist experience: the mobile mundane becomes simultaneously extraordinary and ordinary as the habitual practices are renegotiated when the leisure boaters come to terms and domesticate the space through repetition, production and co-production of the tourist space.

The mobilities perspective offers a lens to develop an analytically useful theory for researching everyday life in a tourism context, and we apply it to the case of canal tourism. In doing so, we extend the literature on mundane mobilities, which has thus far mainly focused on automobilities and commuting, to study tourism and leisure. We contribute to the literature on waterways tourism and leisure, which is seldomly researched ethnographically, especially canal boating. This study has helped us to better understand how mundanity comes into being in the leisure spaces and through practices that are simultaneously ordinary and extraordinary; it has also revealed opportunities for future research regarding inland waterways tourism. Currently we present a holistic analysis of mundane mobilities in canal 
tourism context. Future research could study canal (as well as river) boating as second home tourism, and analyse how various demographic characteristics, such as gender, age and disability mediate the boaters' (embodied) practices. Different ways of perceiving the canal environment on self-driven compared to skippered as well as catered 'hotel' and 'hostel' boats could also be studied. This paper focused on the interior boatspace of the narrowboat, however the interaction between the boaters, boat and the wider canal environment, i.e. material agencies and sociabilities, also need further study.

\section{Figures}

Figure 1. Holiday boaters Sue, Janet and Derek travelling on 70ft narrowboat Olympic on the Macclesfield Canal. Photo: Maarja Kaaristo, 2016.

Figure 2. Canal and river network in northern England. Map data (C) 2016, Google (Canal and River Trust, 2016).

Figure 3. Holiday boater Phil preparing breakfast in the galley. Photo: Maarja Kaaristo, 2016.

\section{Acknowledgements}

We are very grateful to Tim Edensor and Ben Bowles for their comments on various drafts of this article as well as to the two anonymous reviewers for their insightful suggestions that really helped to strengthen the paper. The lead author would also like to thank all the interviewed boaters and other people she has met while on and near the canals of Manchester and the Pennines.

\section{Manuscript sources}

Interviews (recordings and transcripts) and fieldwork diaries from 2014-2016 (in the possession of the lead author).

\section{Disclosure statement}

No potential conflict of interest was reported by the authors. 


\section{Bibliography}

Adler, P. \& Adler, P. (1987) Membership roles in field research. Newbury Park, CA: Sage.

Anderson, J. \& Peters, K. (2014) Water worlds: human geographies of the ocean. Farnham, Burlington: Ashgate.

Anim-Addo, A., Hasty, W. \& Peters, K. (2014) The Mobilities of Ships and Shipped Mobilities. Mobilities, 9(3), 337-349.

Bagwell, P. S. \& Lyth, P. J. (2006) Transport in Britain: from canal lock to gridlock. London: Hambledon and London.

Binnie, J., Edensor, T., Holloway, J., Millington, S. \& Young, C. (2007) Mundane mobilities, banal travels. Social \& Cultural Geography, 8(2), 165-174.

Bissell, D. (2014) Transforming commuting mobilities: the memory of practice. Environment and Planning A, 46, 1946-1965.

Bowles, B. (2014) Dangerous Waters: Security Threats and Their Role in Community Formation among Itinerant Boat Dwellers on the Waterways of Southern England. Student Anthropologist, 4(1), 6-17.

Bowles, B. (2016) 'Time Is Like a Soup': Boat Time and the Temporal Experience of London's Liveaboard Boaters. The Cambridge Journal of Anthropology, 34(2), 100-112, DOI: $10.3167 /$ ca.2016.340110

Büscher, M., Urry, J. \& Witchger, K. (2011) Mobile methods. Abingdon, New York: Routledge.

Canal and River Trust (2015) Canal \& River Trust Trustees' Annual Report and Accounts 2014/15. Milton Keynes: Canal and River Trust.

Canal and River Trust (2016) https://canalrivertrust.org.uk/enjoy-the-waterways/canal-andriver-network (Accessed 28.05.2016)

Cary, S. H. (2004) The tourist moment. Annals of Tourism Research, 31(1), 61-77.

Cohen, E. (1979) A Phenomenology of Tourist Experiences. Sociology, 13(2), 179-201.

Coles, R., Millman, Z., \& Flannigan, J. (2013) Urban landscapes - everyday environmental encounters, their meaning and importance for the individual. Urban Ecosyst, 16, 819-839. 
Cresswell, T. (2006) On the move: mobility in the modern Western world. New York: Routledge.

Crouch, D. (2001) Spatialities and the feeling of doing. Social \& Cultural Geography, 2(1), $61-75$.

Dewalt, K. M., Dewalt, B. R. \& Wayland, C. B. (1998) Participant Observation. In Bernard, H. R. (Ed.) Handbook of Methods in Cultural Anthropology. Walnut Creek, CA: AltaMira, 259-299.

Douglas, M. (1966) Purity and Danger: an Analysis of pollution and taboo. London: Routledge \& Keegan Paul.

Dwyer, S. C. \& Buckle, J. L. (2009) The Space Between: On Being an Insider-Outsider in Qualitative Research. International Journal of Qualitative Methods, 8(1), 54-63.

Edensor, T. (2001) Performing tourism, staging tourism: (Re)producing tourist space and practice. Tourist Studies, 1, 59-81.

Edensor, T. (2006) Sensing Tourist Spaces. In Minca, C. and Oakes, T. (Eds.) Travels in Paradox: Remapping Tourism. Lanham etc.: Rowman \& Littlefield Publishers, 23-45. Edensor, T. (2007) Mundane mobilities, performances and spaces of tourism. Social \& Cultural Geography, 8(2), 199-215.

Edensor, T. (2010) Introduction: Thinking about Rhythm and Space. In Edensor, T. (Ed.) Geographies of Rhythm. Nature, Place, Mobilities and Bodies. Farnham, Burlington: Ashgate, 1-18.

Falconer, E. (2012) Embodiment and Emotion in the Experiences of Independent Women Tourists. A thesis for the degree of Doctor of Philosophy. Manchester: Manchester Metropolitan University.

Fallon, J. (2012) 'If You're Making Waves Then You Have to Slow Down': Slow Tourism and Canals. In Fullagar, S., Markwell, K. \& Wilson, E. (Eds.) Slow Tourism. Experiences and Mobilities. Bristol, Buffalo, Toronto: Channel View Publications, 143-154.

Franklin, A. \& Crang, M. (2001) The trouble with tourism and travel theory? Tourist Studies, $1,5-22$. 
Fyall, A., Oakley, B. \& Weiss, A. (2000) Theoretical Perspectives Applied to InterOrganisational Collaboration on Britain's Inland Waterways. International Journal of Hospitality \& Tourism Administration, 1:1, 89-112.

Gale, T. (2008) The End of Tourism, or Endings in Tourism? In Burns, P. M. \& Novelli, M. (Eds.) Tourism and Mobilities. Local-Global Connections. Wallingford, Cambridge, MA: CABI, 1-14.

Gennep, A. (1960) The Rites of Passage. Chicago: University of Chicago Press.

Gramigna, R. (2013) Toilets, Boundaries, Dirt and Other Disgusting 'Things': A Semiotic Approach. In Kannike, A. \& Laviolette, P. (Eds.) Things in Culture, Culture in Things. Approaches to Culture Theory 3, Tartu: University of Tartu Press, 256-279.

Hadfield, C. \& Biddle, G. (1970) The canals of north west England. Newton Abbot: David \& Charles.

Hall, C. M. \& Härkönen, T. (2006) Lake Tourism: an integrated approach to lacustrine tourism systems. Bristol, Ontario: Channel View Publications.

Hall, C. M. (2008) Of Time and Space and Other Things: Laws of Tourism and the Geographies of Contemporary Mobilities. In Burns, P. M. and Novelli, M. (Eds.) Tourism and Mobilities. Local-global connections. Wallingford, Cambridge, MA: CABI, 15-32.

Hannam, K., Sheller, M. \& Urry, J. (2006) Editorial: Mobilities, Immobilities and Moorings. Mobilities, 1(1), 1-22.

Johns, N. \& Clarke. V. (2001) Mythological Analysis of Boating Tourism. Annals of Tourism Research, 28(2), 334-359

Jordan, S. (2015) 'Relational Space' and the Concept of 'Belonging'. Writing In Practice. The Journal of Creative Writing Research, 1. Available at:

http://www.nawe.co.uk/DB/current-wip-edition/articles/writing-the-smart-city-relationalspace-and-the-concept-of-belonging.html (Accessed: 22.02.2016)

Klein, R. (2008) Paradise Lost at Sea: Rethinking Cruise Tourism. Halifax: Fernwood Publishing Co.

Kleinert, M. (2009) Solitude at Sea or Social Sailing? The Constitution and Perception of the Cruising Community. In Vannini, P. (ed.) The Cultures of Alternative Mobilities. Routes Less Travelled. Farnham, Burlington: Ashgate, 159-175. 
Larsen, J. (2008) De-exoticizing tourist travel: Everyday Life and Sociality on the Move. Leisure Studies, 27(1), 21-34.

Leone, M. (2012). The Semiotics of Waste World Cultures. On Traveling, Toilets, and Belonging. Cultura. International Journal of Philosophy of Culture and Axiology. 9(2), 237258.

Löfgren, O. (2008) The Secret Lives of Tourists: Delays, Disappointments and Daydreams. Scandinavian Journal of Hospitality and Tourism, 8:1, 85-101.

Longhurst, R. (2000) Bodies. Exploring Fluid Boundaries. London, New York: Routledge. MacCannell, D. (1999) The tourist: a new theory of the leisure class. Berkeley, CA, London: University of California Press.

Maritime and Coastguard Agency (2014) Ships and cargoes - guidance. Inland waterways and categorisation of waters. Available at: https://www.gov.uk/guidance/inland-waterwaysand-categorisation-of-waters (Accessed: 22.02.2016)

Maslow, A. H. (1962). Toward a psychology of being. Princeton, NJ: Van Nostrand. McCabe, S. (2002) The Tourist Experience and Everyday Life. In Dann, G. M. S. (Ed.) The Tourist as a Metaphor of the Social World. Oxon, New York: CAB International, 61-75. McCormack, D. (2008) Geographies for Moving Bodies: Thinking, Dancing, Spaces. Geography Compass, 2/6, 1822-1836.

Merriman, P. (2009) Automobility and the Geographies of the Car. Geography Compass, 3/2, $586-599$.

Mikkelsen, M. V. \& Cohen, S. A. (2015) Freedom in mundane mobilities: Caravanning in Denmark. Tourism Geographies, 17(5), 663-681.

Monahan, D. L. \& Spencer, C. 2004. From trade to tourism: the Rochdale Canal, 1794-2004. Transactions of the Halifax Antiquarian Society, 12, 31-47.

Mosse, J., Frew, C. \& Malcolm, A. (2013) Waterways Guide 5. North West \& the Pennines. Glasgow: Nicholson.

Nansen, B., Arnold, M., Gibbs, M. \& Davis, H. (2010) Time, space and technology in the working-home: an unsettled nexus. New Technology, Work and Employment, 25(2), 136-153. 
Obrador, P. P. (2003) Being-on-holiday: Tourist dwelling, bodies and place. Tourist Studies, $3,47-66$.

Prideaux, B. \& Cooper, M. (2009) River tourism. Wallingford, Cambridge, MA: CABI.

Quan, S. \& Wang, N. (2004) Towards a Structural Model of the Tourist Experience: An Illustration from Food Experiences in Tourism. Tourism Management, 25(3), 297-305

Ryan, C. (2010) Ways of conceptualising the tourist experience - A review of literature. Tourism Recreation Research, 35(1), 37-46.

Sampson, H. \& Thomas, M. (2003) Risk and responsibility. Qualitative Research, 3(2), 165189

Sheller, M. \& Urry, J. (2006) The new mobilities paradigm. Environment and Planning A, $38(2), 207-226$.

Shipley, R. (1999) Making a silk purse from a sow's ear: lessons from the failure to develop the Welland Canal as a tourism resource. Environments, 27(2), 25-44.

Tang, L. \& Jang, S. (2010) The Evolution from Transportation to Tourism: The Case of the New York Canal System. Tourism Geographies, 12(3), 435-459.

Uriely, N. (2005). The tourist experience: Conceptual Developments. Annals of Tourism Research, 32(1), 199-216.

Urry, J. (2007) Mobilities. Cambridge, Malden: Polity Press.

Urry, J. \& Larsen, J. (2011) The Tourist Gaze 3.0. Los Angeles, London, New Delhi, Singapore, Washington DC: Sage.

Vannini, P. (2012) Ferry tales: mobility, place, and time on Canada's west coast. London: Routledge.

Wang, N. (1999) Rethinking authenticity in tourism experience. Annals of Tourism Research, 26(2) pp. 349-370.

Williams, S. \& Lew, A. A. (2015) Tourism Geography. Critical Understandings of Place, Space and Experience. London \& New York: Routledge. 